\title{
The Causes and Solutions of "Low Level Trap" in Food Manufacturing Industry: Based on the Perspective of Industrial Commons
}

\author{
Li-hua LI ${ }^{1}$ \\ School of Economics and Management, Tianjin University \\ of Science and Technology \\ No.1038, Southern Dagunan Road, Hexi District, Tianjin \\ 300222, China
}

\author{
Yi-qing $\mathrm{SU}^{2 *}$ \\ China Institute for Rural Studies, Tsinghua University, \\ Beijing 100084, China \\ E-mail: syq_005@163.com
}

\begin{abstract}
This paper takes "the Wave Phenomenon" as the breakthrough point, based on the perspective of industry Commons, using analysis method of Microeconomics, discussing "Low Level Trap" formation mechanism of food manufacturing industry in our country, obtains the following three conclusions: first, in the absence of government regulation, the wave phenomenon led to the emerging food industry overcapacity; Second, the excess capacity reduce the margins on the food manufacturing enterprise, resulting of the insufficient supply of industry commons core resource, which made promoting the development of food manufacturing and transformation and upgrading of the industrial Commons not be formed; Third, insufficient supply of industry commons core resource has led to the inability of food manufacturers to organize innovation activities, thus making them "low level traps". Finally, this paper puts forward corresponding policy Suggestions from the aspects of legal regulation, the industrial commons resources cultivation and the improvement of enterprises' ability on their own.
\end{abstract}

Keywords-Food Manufacturing Industry; Wave Phenomena; Industrial Commons; Competitiveness

\section{INTRODUCTION}

Food industry is an important pillar industry in China's national economy. In recent years, however, the growing is slow with the appearance of macroeconomic along with the "new normal", and most urban residents are becoming saturated with food consumption, which put forward new challenges to the development of food industry. Among them, the "low level trap" of China's food manufacturing industry in the new economic situation has always been an obstacle to the transformation and development of the whole food industry. The "low level trap" in China's food manufacturing industry is in essence inadequate innovation under the new demand structure. In many people's view, the strategy that China's food manufacturing industry adopted the "market for technology" has begun to fail, and they even predicted that China's food industry is at the bottom on the eve of the outbreak. So far, although existing literature are analyzed in detail the "low level trap" forms of food manufacturing and related causes, but these are based on the phenomenon observation and case induction, lacking of accurate diagnosis of the existing problems and discussion in theory. Therefore theoretically in-depth analyzing the reasons of China's food industry "low level trap", analyzing the specific formation mechanism, based on this, it is of great significance for China's food industry and future economic development to formulate countermeasures to help the food manufacturing industry break through the existing difficulties.

\section{COMPREHENSIVE REVIEW}

As for the current dilemma faced by China's food manufacturing industry, many scholars have interpreted it from different perspectives and can be divided into four aspects:

First, low real productivity is the main reason for the difficulties. Overall, most of our manufacturing enterprises engaged in labor-intensive, low technology-intensive products, its labor productivity is 38000 yuan per person per year, it is $4 \%$ of the labor productivity of United States and Japan, Germany' labor productivity 5.5\% [1] . Abundant labors supply with low price, and further inhibit the enterprise technology creativity, with the rise of labor price, only rely on low labor costs low efficiency production is difficult to realize the sustainable and healthy development of industry [2]. Entering the dependent of "new normal" of economy, the labor intensity of China's food manufacturing industry is still rising, which further depresses the growth of productivity [3].

Second, the most critical factor in the formation of difficulties is weak innovation ability. Without creativity, Chinese food manufacturing will not increase the value to the product. At present, many food enterprises in our country have the problems of insufficient investment and imbalance in innovation resources, which greatly restricts the expansion of technological innovation and research and development activities, resulting in poor innovation effect [4]. Even the Yangtze River delta region, which has a high manufacturing level, is faced with the shortage of innovative talents. In addition, many Chinese food companies are victims of "buy rather than build" thinking. They do not chose to create an exclusive skills, but choose "buy" advantage from other sources, we can catch a glimpse that from a macro perspective, 
China's manufacturing enterprises patent applications increased rapidly, but the quality of patents is relatively lagging behind[5].

Thirdly, the lack of competitive advantage is the most important reason for dilemma formation. Since the innovation ability that China's food manufacturing competitiveness depends on is weak, mostly it is just the international manufacturing base for rough machining, so there is no control on the competition over most of the food enterprises in China, that is to say, the lack of control for core technology in food manufacturing [6]. Our country's food manufacture has been carrying out the passive "factory" mode of production without thought, and obviously its products are not competitive with the products made by the concept and innovation [7].

Fourth, the most fundamental cause of the dilemma is the improper selection of innovative approaches. In terms of innovation selection, different countries have different choices: the United States focuses on basic scientific research, which has produced a number of source innovations, and has produced many Nobel Prize winners [8]. Technological innovation takes enterprises as the main body, based on the market. Because of the technological strength and national strength of the United States, the American model is extremely difficult to replicate. France and Germany have chosen the technical route, although they won't win many Nobel prizes at home, but they have a lot of competitive products. Japan and South Korea have taken the "introduction - digestible - reinnovation" model in the context of technological research and development. China admires the US model and relies heavily on the transformation of the results of universities and research institutes, but the innovative market base is not enough, and most technology-driven innovations take little effect. And the introduction technology does not pay attention to creation, fall into the dependency trap of "introduction - backward reintroduction". Therefore, the choice of the innovation path also severely restricts the development of China's food manufacturing industry.

To sum up, although scholars analyzed the difficulties that China's food industry are facing, its explanation is proposed on the summary of the phenomenon, There is no systematic explanation of the dilemma from the theoretical level, And there is no constructive view on breaking through the predicament. This shows that previous analysis of the causes of the "low level trap" for food manufacturing has not to the point. In view of this, this article will use Gary p. Pisano [9] "industry Commons" theory put forward to the analyze China's food manufacturing the formation mechanism of "low level trap", so as to provide relief for the transformation and upgrading of China's food manufacturing.

\section{THE CAUSE ANALYSIS OF "LOW LEVEL TRAP" IN CHINESE FOOD MANUFACTURING INDUSTRY}

\section{A. The cause of products excess capacity: wave phenomena}

Most of China's food manufacturing industry is suffering from overcapacity. How is overcapacity produced? We explained the wave phenomenon put forward by Lin yifu [10] [11].Due to a lack of supporting industrial policies for "the wave phenomenon" industry, there are no barriers for the enterprise to entry into the industry, and "the wave phenomenon" leading to excessive entry process is shown in Figure 1. Assuming that all enterprises in an industry have constant marginal cost $c$, the market demand is $p=D(Q)$. At the beginning, there are reigning enterprise, and the output of each enterprise is $q_{n}$, the total output is $n q_{n}$, the price is $p_{n}=D\left(n q_{n}\right)$ Now, with the wave phenomena, other companies to enter the market one after another, we analyze the most extreme cases: another enterprise to enter the market, the output of each enterprise becomes $q_{n+1}$, the total production is $(n+1) q_{n+1}$, the price falls by $p_{n+1}$. Before and after entering, the added value of the total social surplus (excluding entry costs) $\triangle S=S_{A C D G}-S_{A B E G}=S_{B C I}+S_{C D E I}$, that is the added value of the total social surplus is equal to the difference between the trapezoid $A C D G$, and the trapezoid area, also is equal to the sum of the area of the triangle $B C I$ and rectangle are $C D E I$. Thus, the profit of the new entrants may be showed as:

$$
\begin{aligned}
\pi_{n+1} & =\left(p_{n+1}-c\right) q_{n+1}=\left(p_{n+1}-c\right)\left(n q_{n+1}+q_{n+1}-n q_{n+1}\right) \\
& =\left(p_{n+1}-c\right)\left[(n+1) q_{n+1}-n q_{n+1}\right] \\
& =S_{C D F H}
\end{aligned}
$$

As can be seen from Figure 1, the total surplus value added $\Delta S<S_{C D F H}$, that is, the private income of the enterprise is greater than the social gain generated by its entry. This means that the entry decisions of new enterprises have externalities. The entry cost $k$ meet: $\Delta S<k<S_{C D F H}$ the entering enterprise is profitable, but from the point of view from society, entry causes the loss of the society welfare. The specific reasons can be explained as followings: because new enterprises enter and make their own profits at the same time, resulting in a decline in profits of other enterprises in the industry, and the declining profits can be shown $S_{\text {decline }}=\left[\left(p_{n+1}-c\right) \cdot n q_{n+1}+\left(p_{n}-p_{n+1}\right) \cdot n q_{n}\right]$ in Figure 1. But entering the enterprise will only consider its own private income on the margin, so it will not consider the decline of other enterprises' profits. So as long as the entry is advantageous to the new entrants, without the barriers to entry, it will attract a large number of enterprises to enter, causing that the profits of the first entrants in the industry are continuously damaged. We naturally think of such a phenomenon the Hardin [12] on the description of the "tragedy of the Commons", and "tragedy of the Commons" described are of a similar story in "the wave phenomenon", enterprises continue to enter the free industries without barrier, leading to excessive entry into the industry. 


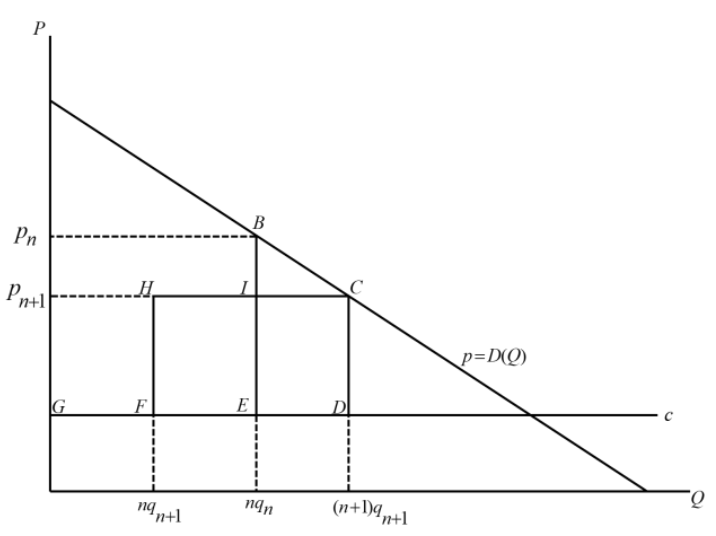

Fig. 1. Free access and benefits

At the start of every wave of "wave phenomena ", every business expects a high return on its investment, and financial institutions are willing to support these investment projects under the influence of "herd behavior". However, after completion of each enterprise investment, large quantity of enterprise, excessive investment industry will inevitably appear overcapacity, enterprise bankruptcy, and the worst effects of the number of bank non-performing loans increased sharply the serious consequences. Moreover, even in the existing industry has a large surplus of production capacity, deflation, for the next "the wave phenomenon" in the emerging industry investment may also continue to happen, this makes the new industries in developing countries, such as emerging food manufacturing, frequently being in a dilemma of excess capacity.

\section{B. Tragedy of "industrial Commons": insufficient supply of industry core resources}

How can overcapacity affect the development of industries in developing countries? Here we will use the concept of "industrial Commons" to explain. Industrial Commons refers to those enterprises who are able to support the industry development, a collection of labor, organization, technology, and manufacturing capacity Shared by multiple industries and even the entire industry. Pisano pointed out that the industry "commons" rooted in consumers, suppliers, partners, technical workers and local institutions (such as universities), sharing for those who need the ability of industry, industrial competitiveness is the source of industrial commons. In the auto industry, for example, in a specific area, the car manufacturers need from common suppliers and human resources "nourishment", although these are not open pastures as industrial resources for free, but they can achieve coexistence and co-prosperity with many enterprises [9]. If the level of manufacturing of precision machining parts in the automotive industry becomes weaker, or the number of first class engineers in the labor force decreases, then companies that demand precision machining parts will suffer losses.

It can be seen that if a country wants to improve the competitiveness of its industry, it must cultivate the industrial public land for industrial development and upgrading. From the definition of industrial commons,
The cultivation of industrial commons is to cultivate the core resources needed for industrial development, which can be shared by multiple enterprises and even the whole industry labor, organization, technology and skills. From this perspective, how is the development of industrial commons of food manufacturing industry in China? We believe that in the case of excess capacity caused by the "wave phenomenon" mentioned in the previous article, there is a serious shortage of the core resource supply of the industry in China's food manufacturing industry. On the one hand, there is no shortage of labor force in China's food manufacturing industry, but the supply of labor quality is worrying. The United States and Japan have invested heavily in national education in the early stage of industrialization, which has improved the basic quality of the labor force, so that enterprises can recruit workers who meet the requirements of production. And our country owing to the complicated conditions, the effect of popularization education has not reached the level of the United States and Japan, the cultural quality of migrant workers engaged in industrial production is not high, so that the food manufacturing industry in our country has been greatly restricted in the supply of labor quality. On the other hand, food manufacturers are pouring money into new industries, making it less profitable to support the formation of technologies and capabilities. Promotion of industrial core technology is the need to invest a lot of money as a support, in the United States food manufacturing industry rapid development stage, private enterprises supporting the development and promotion of these technologies; but in China, due to a new influx of excessive food enterprises in the manufacturing industry, lead the industry product suffered excess production without upgrade before. In the state of surplus production, the meager profits of food manufacturers are not enough to support the transformation and upgrading of products, processes and manufacturing capabilities. Therefore, the sudden entrants can only drag the industry into low-level competition, such as price war, and hinder the supply of the core resources of the industrial commons in the food manufacturing industry.

\section{The formation mechanism of "low level trap" of food manufacturing industry in China}

Based on the above theory, based on the theory of industrial commons, we can summarize the present situation of China's food manufacturing industry as a "low level trap". Its logic is shown in Figure 2. Emerging developing countries, as a result of the advantage of backwardness, enterprises will flood into a new food manufacturing industry. "The wave phenomenon" is caused by excessive entry in the food industry in emerging industries, thus the problem of excess production capacity. Excess capacity increases the cost of entering the enterprise, but it reduces the profit margins of all the enterprises in the food manufacturing industry, and makes the enterprises in the food manufacturing industry suffer losses or even close down. The core resources of the meager profit making the food manufacturing companies to invest in the industry -technology and manufacturing capabilities, therefore can't be effective innovation activities, to enhance the added value of the production of food, the food manufacturing industry or in low value-added food struggle or bankruptcy at a low level of 
competition. Further, according to the "wave phenomenon" of the law, food manufacturing industry into a "low level trap" and other emerging industries "wave phenomenon occurs independently of each other. So our country's food manufacturing industry in this wave of "wave phenomenon" in the core industrial commons sustainable supply of resources shortage, low added value, food industry upgrade difficult trap.

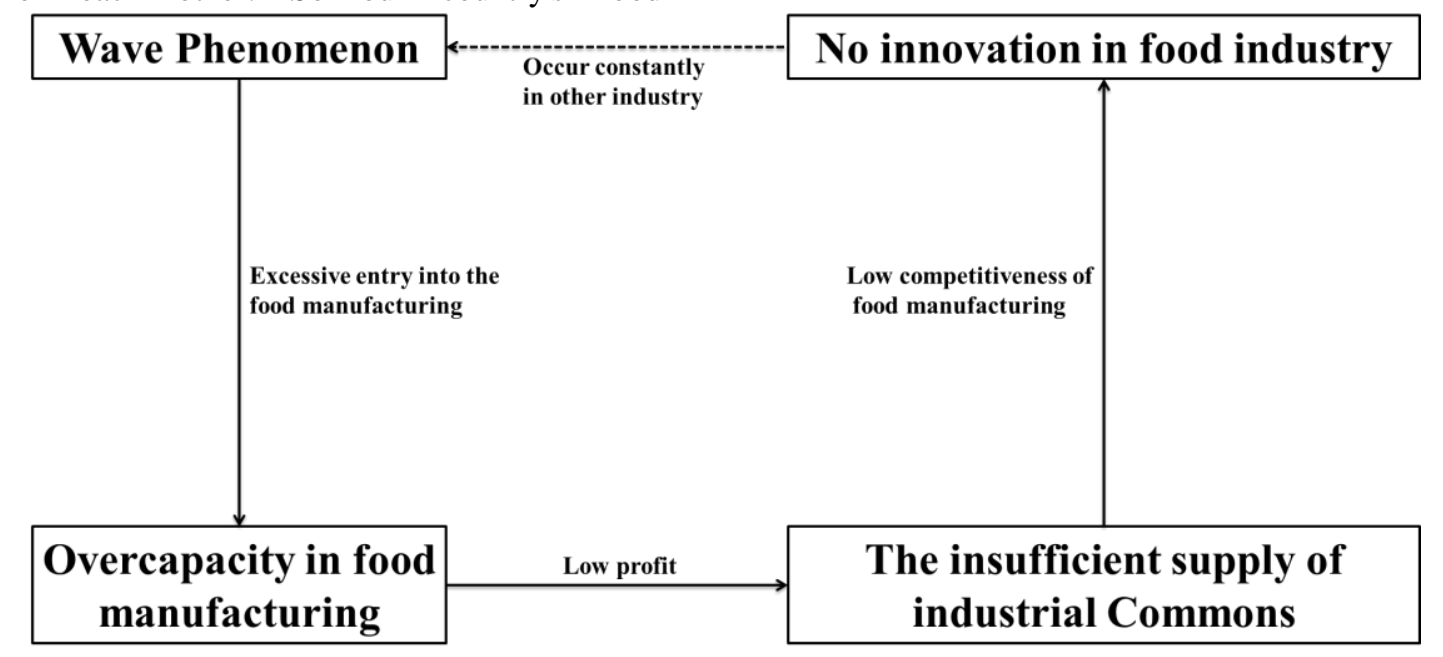

Fig. 2. Formation mechanism of the "low level trap" of food manufacturing industry

\section{CONCLUSION AND POLICY PROPOSAL}

Based on the above conclusions, the following four policy recommendations are proposed: first, improve the legal regulation of the emerging food industry. New and promising industries in developing countries are predictable for the developed world, so the government should make reasonable industrial policy and access mechanisms for emerging food industry in order to ensure there will not be prematurely overcapacity in emerging food industry because of "wave phenomenon". Second, cultivate the core resources of the industry commons. The government should provide policy support and funding in education, infrastructure, technology development, manufacturing process improvement and other aspects, to ensure the effective supply of core resources and to foster industrial commons that belong to Chinese food manufacturing industry, and promote the healthy development of China food manufacturing industry. Third, improve the quality of food manufacturing enterprises. The food manufacturing industry enterprises should make full use of the resources provided by the industry commons, foster their ability in technological R \& D and manufacturing processes, etc, and realize their own competitiveness. Fourth, we should correctly understand the role of food manufacturing in the process of economic development. The lesson from American tells us: the manufacturing sector, especially the manufacturing industry for the cultivation of basic ability of the economic development of a country is essential, We can't be pessimistic about manufacturing because of a temporary "low level trap" in manufacturing, nor can we ignore manufacturing because the manufacturing sector is at the lowest end of the value smile curve. We must pay attention to those who provide industry manufacturing base technology and the ability for other industries and the development of the industry, only in this way can we guarantee the healthy development of China's manufacturing industry of the industry commons, realizing the transformation and upgrading of manufacturing industry.

\section{REFERENCES}

[1] Li Lei. Problems and Countermeasures of China's manufacturing industry [J]. Journal of Chuzhou University, 2006 (4): 61-63.

[2] Hou Meiwen, Liliyong. The dilemma and solutions of China's manufacturing industry under resource constraints $[\mathrm{J}]$. Economic Forum, 2006 (04): 42-44.

[3] Zheng Gechen. Analysis of the current situation of China's food manufacturing industry and Countermeasures [J] Fujian Textile2012 (3): 43-48. (In Chinese)

[4] Wang Jiangtao, Huang Pei. Study on the present situation and Countermeasures of manufacturing innovation in the Yangtze River Delta [J]. Research and Development management, 2010 (03): 96-102. (In Chinese)

[5] Gary Pisano.Wiles. Return to industrial Commons, [J].Business (review), 2014 (12): 44-47. (In Chinese)

[6] Zhu Jianmin. Current situation and Countermeasures of the control power of manufacturing competitiveness in China [J]. Economics, 2014 (03): 39-44. (In Chinese)

[7] Jia Shan. Study on the international competitiveness of China's food manufacturing industry [J]. Guangdong Agricultural Science, 2011, 38 (20): 198-200. (In Chinese)

[8] Dong Dashan, Yu Hao. Study on the present situation and development of China's manufacturing industry [J]. Shanghai Economic Research, 2008, 09:36-40. (In Chinese)

[9] Pisano G, Shih W. Producing Prosperity: Why America needs a Manufacturing Renaissance [M]. Harvard Business Review Press, 2012.

[10] Yifu Lin. To construct [J]. Re-construction of the Wave Phenomenon and Developing Macroeconomic theory, Economic Research 2007,01:126-131. (In Chinese)

[11] Yifu Lin, Wu Xing, Yiqing. Wave Phenomenon and the Formation Mechanism of Excess Capacity [J]. Economic Research, 2010, 10:4-19. (In Chinese)

[12] Hardin G. The Tragedy of the Commons [J]. Science, 1968, 162(3859): 1243-1248. (In Chinese) 